\title{
Investigation of the mechanisms leading to the 2017 Montreal flood
}

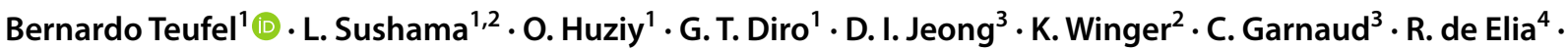 \\ F. W. Zwiers ${ }^{5,6} \cdot$ H. D. Matthews ${ }^{7} \cdot$ V.-T.-V. Nguyen ${ }^{1}$
}

Received: 27 December 2017 / Accepted: 30 July 2018 / Published online: 14 August 2018

(c) The Author(s) 2018

\begin{abstract}
Significant flood damage occurred near Montreal in May 2017, as flow from the upstream Ottawa River basin (ORB) reached its highest levels in over 50 years. Analysis of observations and experiments performed with the fifth generation Canadian Regional Climate Model (CRCM5) show that much above average April precipitation over the ORB, a large fraction of which fell as rain on an existing snowpack, increased streamflow to near record-high levels. Subsequently, two heavy rainfall events affected the ORB in the first week of May, ultimately resulting in flooding. This heavy precipitation during April and May was linked to large-scale atmospheric features. Results from sensitivity experiments with CRCM5 suggest that the mass and distribution of the snowpack have a major influence on spring streamflow in the ORB. Furthermore, the importance of using an appropriate frozen soil parameterization when modelling spring streamflows in cold regions was confirmed. Event attribution using CRCM5 showed that events such as the heavy April 2017 precipitation accumulation over the ORB are between two and three times as likely to occur in the present-day climate as in the pre-industrial climate. This increase in the risk of heavy precipitation is linked to increased atmospheric moisture due to warmer temperatures in the present-day climate, a direct consequence of anthropogenic emissions, rather than changes in rain-generating mechanisms or circulation patterns. Warmer temperatures in the present-day climate also reduce early-spring snowpack in the ORB, offsetting the increase in rainfall and resulting in no discernible change to the likelihood of extreme surface runoff.
\end{abstract}

\section{Introduction}

Destructive springtime floods occurred in the Canadian provinces of Quebec and Ontario in 2017, causing insured damages exceeding 220 million CAD (Insurance Bureau of Canada 2017). In Quebec, 286 municipalities were affected by flooding that inundated at least 5300 residences and forced over 4000 people to evacuate their homes (Québec Government 2017). This includes significant damage due to widespread flooding near Montreal, at the confluence of

Bernardo Teufel

bernardo.teufel@mail.mcgill.ca

McGill University, Montreal, Canada

University of Quebec at Montreal, Montreal, Canada

3 Environment and Climate Change Canada, Toronto, Canada

Servicio Meteorológico Nacional, Buenos Aires, Argentina

University of Victoria, Victoria, Canada

Pacific Climate Impacts Consortium, Victoria, Canada

Concordia University, Montreal, Canada the Saint Lawrence and Ottawa rivers (Fig. 1), during the first half of May.

The Saint Lawrence river flows from the Great Lakes to the Atlantic Ocean and is the largest river in the floodaffected region. The flow in this river is heavily regulated, and while spring 2017 flows were well above-normal at Montreal, they were not record-breaking. One of the main factors that contributed to high flows in the Saint Lawrence river was the outflow from the Great Lakes, which was at the highest levels allowed by regulation.

The Ottawa River basin (ORB) covers $146,300 \mathrm{~km}^{2}$ of southern Quebec and eastern Ontario, making the Ottawa river one of the main tributaries to the Saint Lawrence. A few dozen reservoirs in the ORB provide partial flow regulation, primarily for the northern tributaries to the Ottawa river, while most of the southern tributaries remain unregulated. In May 2017, flow at the outlet of the ORB reached its highest levels in over 50 years of measurements, exceeding the previous maximum from 1976 by around $8 \%$. Water levels in the Lake of Two Mountains, which connects the Ottawa and Saint Lawrence rivers, were also historically high, exceeding the previous 


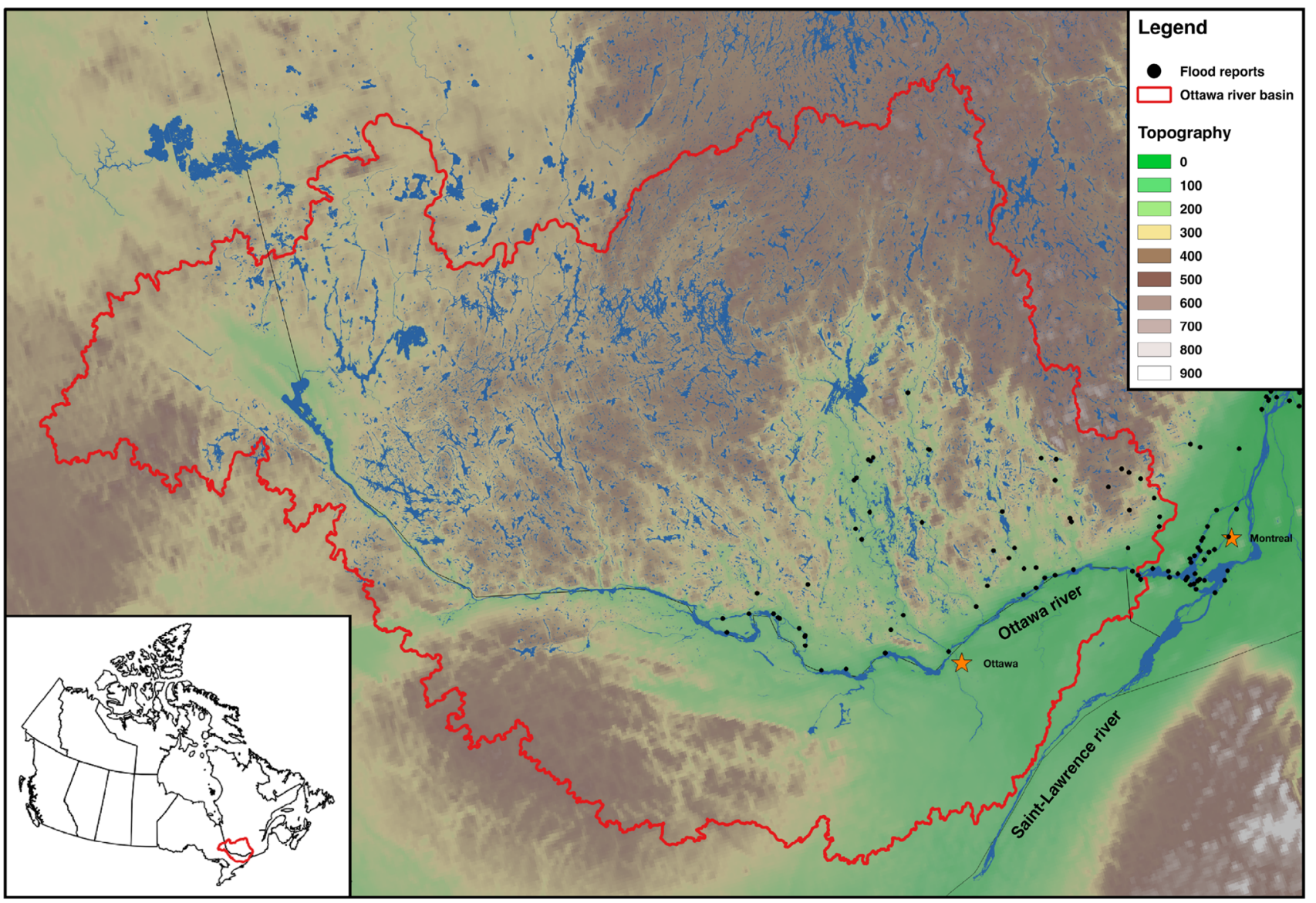

Fig. 1 Locations in southern Quebec affected by the 2017 springtime flood event (black dots indicate locations where flooding was reported), with the Ottawa River basin outlined in red. The inset shows the location of the basin within Canada. The colours show the topography, in meters

maximum by over $20 \mathrm{~cm}$. The record-breaking flow from the ORB was the main driver of the flooding reported near Montreal.

Factors that are likely to have contributed to extreme flows from the ORB include spring snowmelt, above-average precipitation during the month of April and heavy precipitation during the first week of May. The goal of this paper is to investigate the mechanisms leading to the Montreal flood, through targeted experiments with the fifth generation Canadian Regional Climate Model (CRCM5), complemented by the analysis of observational datasets. Using the 'attributable risk' approach to event attribution (e.g., Stott et al. 2004), the role that anthropogenic greenhouse gas emissions may have played in increasing or decreasing the probability of occurrence of the 2017 flood event is also assessed.

The rest of the paper is organized as follows. Section 2 describes the model used in this study. Section 3 outlines the various experiments performed and Sect. 4 discusses the observed and modelled evolution of the event. Section 5 presents the results from sensitivity experiments, while Sect. 6 presents the event attribution results, followed by a summary and conclusions in Sect. 7.

\section{Model}

The regional climate model used in this study is CRCM5 (Martynov et al. 2013), which is based on the Global Environment Multiscale (GEM) model used for numerical weather prediction at Environment and Climate Change Canada (Cote et al. 1998). It employs semi-Lagrangian transport and a (quasi) fully implicit time stepping scheme. In its fully elastic nonhydrostatic formulation (Yeh et al. 2002), it uses a vertical coordinate based on hydrostatic pressure (Laprise 1992). In this study, the CRCM5 physics package includes: deep convection following Kain and Fritsch (1990), shallow convection based on a transient version of the Kuo (1965) scheme (Belair et al. 2005), large-scale condensation (Sundqvist et al. 1989), correlated $\mathrm{K}$ solar and terrestrial radiation ( $\mathrm{Li}$ and Barker 2005), subgrid-scale orographic gravity wave drag (Mcfarlane 1987), low-level orographic blocking (Zadra et al. 2003), and turbulent kinetic energy closure in the planetary boundary layer and vertical diffusion (Benoit et al. 1989; Delage and Girard 1992; Delage 1997). 
CRCM5 is generally used in a limited area (LAM) configuration, as adequate lateral boundary conditions are usually available. However, the model can also be used in a global variable-resolution (GVAR) mode, with high resolution over the region of interest. For example, Caron et al. (2011) used the GVAR configuration to study tropical cyclones, Markovic et al. (2012) assessed the added value of GVAR in the context of seasonal forecasts and Teufel et al. (2017) made use of GVAR to quantify the influence of anthropogenic emissions on the 2013 Alberta flood event. This study uses the LAM configuration at $0.1^{\circ}$ resolution for most experiments, except for event attribution experiments, which use the GVAR configuration with $0.5^{\circ}$ resolution over North America and $2^{\circ}$ elsewhere. These resolution choices were driven by constraints in physical parameterizations and computing resources. Previous studies (e.g. Teufel et al. 2017) have shown satisfactory performance of CRCM5 at these resolutions.

CRCM5 uses the CLASS v3.5 land surface scheme (Verseghy 2011) and the modified WATROUTE hydrological routing scheme (Soulis et al. 2000; Poitras et al. 2011). The flow directions, river lengths and slopes required by the routing scheme are derived from the HydroSHEDS database (Lehner et al. 2008), available at 30-arcsecond spatial resolution, following the upscaling method employed by Huziy et al. (2013). Sub-grid lakes are represented using FLake (Mironov 2008), a one-dimensional lake model, while the three-dimensional ocean model NEMO (Madec 2008) is used for the Great Lakes, in order to simulate the circulation patterns that can impact lake temperature and lake ice in large lakes.

\section{Methods}

This study explores the mechanisms behind the Ottawa River basin (ORB) flood event through the analysis of observations and CRCM5 experiments. A five-member reference ensemble of CRCM5 simulations is used to evaluate the model performance, including the role of internal variability. The ensemble members differ only in their initial conditions, being initialized $6 \mathrm{~h}$ apart between 0000 UTC $31 \mathrm{March}$ and 0000 UTC 01 April 2017, continuing until 0000 UTC 19 May 2017. Similar five-member ensembles are performed for each sensitivity test, described below, to help assess the significance of the various factors that may have contributed to the flood event.

Previous studies (e.g., Alexandru et al. 2009) have shown that regional climate models may develop a variety of solutions compatible with a single set of surface and lateral boundary conditions. This effect is usually called internal variability. Some of these solutions may not necessarily be realistic and techniques have been developed to reduce this variability without hampering the abilities of regional models to create high-resolution fields (e.g., Storch et al. 2000). The CRCM5 reference ensemble described above allows for monitoring of internal variability. A large spread among simulations compared to the signal found in each experiment would indicate that the initial and boundary conditions do not provide sufficient guidance to the model to control the evolution of the simulated state. In contrast, a small spread indicates that model results are a direct effect of boundary conditions and that spurious solutions of stochastic origin are being avoided.

The simulations are performed in LAM mode with $0.1^{\circ}$ resolution (Fig. 2a), being initialized and driven at the lateral boundaries by the 6-h Canadian Meteorological Centre (CMC) analysis at $33 \mathrm{~km}$ horizontal resolution, chosen due to its immediate availability after the flood event. Spectral nudging is applied to the temperature field and the horizontal wind components, with a half-response wavelength of $410 \mathrm{~km}$ and a relaxation time of $24 \mathrm{~h}$. Nudging strength is set to zero at the surface and increases with height, reaching full strength above the lowest $15 \%$ of the atmospheric column's mass. All fields describing the initial state of the land surface are taken from a continuous ERA-Interim (Dee et al. 2011) driven run of CRCM5 over the same domain, with the exception of snowpack mass, depth and temperature, which are taken from the Snow Data Assimilation System (SNODAS; Barrett 2003). Preliminary simulations showed improved performance in simulating streamflows when SNODAS fields were used.

\subsection{Reference simulations}

The performance of the CRCM5 reference ensemble in representing several important characteristics of the event is assessed. To this end, the simulated precipitation is first compared to the 6-h Canadian Precipitation Analysis (CaPA; Mahfouf et al. 2007), available at $10 \mathrm{~km}$ spatial resolution. As CaPA does not include information on precipitation phase, SNODAS data is used to evaluate the magnitude of the rain-on-snow event. The 6-h ERA-Interim reanalysis is used to assess synoptic and dynamic features, such as geopotential heights, upper and lower level circulations. Finally, the hydrographs generated by CRCM5 are compared to those from monitoring stations in the areas of interest.

To put the flood into a climatic perspective, temperature data from the Global Historical Climatology Network (GHCN), precipitation data from the Global Precipitation Climatology Centre (GPCC) and snow data from CMC are used to classify the conditions of 2017 into quintiles: much above average, above average, near average, below average and much below average, with respect to the 1981-2010 period. This classification is performed separately for each dataset. A similar analysis is performed 

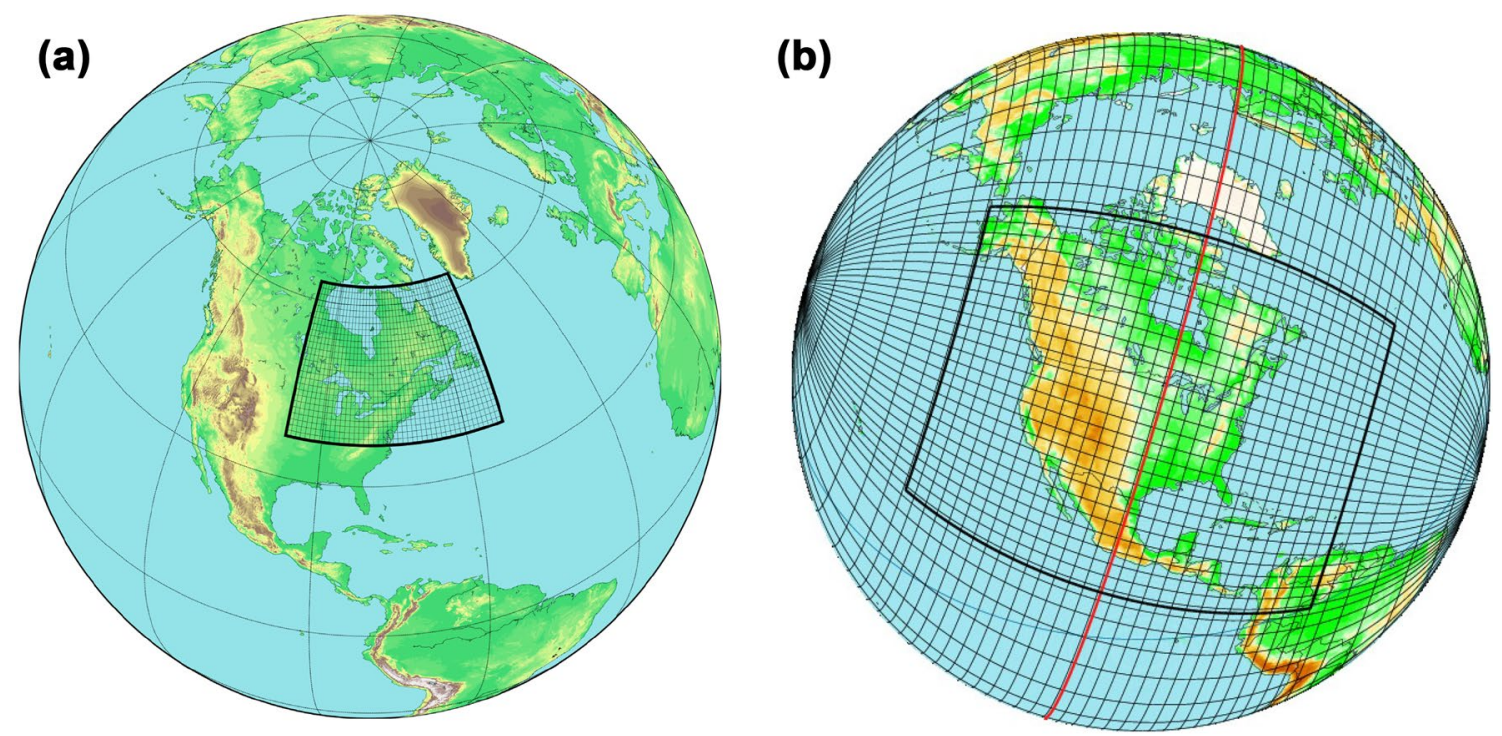

Fig. 2 a Experimental domain of CRCM5 simulations in the LAM $0.1^{\circ}$ configuration, with every twentieth grid point shown. b Experimental domain of CRCM5 simulations in the GVAR configuration, with every fifth grid point shown

with the aid of a continuous CRCM5 simulation driven by ERA-Interim, in order to assess whether the model is able to capture the climatological anomalies.

\subsection{Impact of snow mass and distribution on streamflow}

Snow has an important influence on the magnitude and timing of streamflows, as snowmelt may directly contribute to surface runoff and the evolution of snow cover during spring has a large influence on the thawing of the soil column, thus controlling hydraulic conductivity. To assess the role of snow mass and distribution in the ORB on the magnitude and timing of peak flow, experiments are performed where the initial spatial distribution of snow over the ORB is taken from a different year, making use of the SNODAS dataset.

In the first set of experiments, 2013 is chosen as a high-snow year, as average SWE over the ORB in late March was about twice the value of 2017. The year 2012 is chosen as a low-snow year, with about half the SWE of 2017. A second set of experiments uses the same spatial snow distributions for high and low-snow years, but initial snow mass is adjusted to be the same as in 2017. This highlights the impact of snow distribution on soil thawing, infiltration and streamflow, as the snow distribution derived from the high-snow year is more homogeneous than the distribution derived from the low-snow year, which features higher SWE over a smaller snow-covered area.

\subsection{Impact of frozen soil parameterization on simulated streamflow}

In cold regions, frozen soil processes exert a strong control on the infiltration rate and need to be parameterized accurately in order to obtain realistic spring streamflows. Ganji et al. (2017) modified the treatment of frozen water in CLASS to include fractional permeable area, supercooled liquid water and a new formulation for hydraulic conductivity. They found that the improved parameterization results in simulated spring streamflow peaks and timings that are in better agreement with those observed across a number of basins in Quebec. To assess the impact of the improved parameterization of frozen soils on the ORB flood, an experiment without the described modifications is performed, and the magnitude and timing of peak streamflow are compared to those of the reference simulations.

\subsection{Event attribution}

The influence of anthropogenic GHG emissions on the probability of occurrence of the precursors to the ORB flood event is explored. This is accomplished by comparing large ensembles of CRCM5 simulations, in the GVAR configuration (Fig. 2b), for present-day and pre-industrial cases. As in Kay et al. (2011), Christidis et al. (2013) and Teufel et al. (2017), the present-day and pre-industrial ensembles differ in their GHG concentrations, sea surface temperatures (SST), and sea-ice concentrations (SIC). In this study, the ensemble for the present-day case (called IR) uses GHG concentrations corresponding to the year 2017, while SST 
and SIC evolution are taken from CMC analysis for 2017. Three ensembles for the pre-industrial case (called PIRa, $\mathrm{PIRb}$ and PIRc) are considered, where GHG concentrations correspond to their values for 1850, while SST and SIC correspond to pre-industrial conditions.

Pre-industrial SST is obtained by subtracting the SST change attributable to anthropogenic forcing from the 2017 CMC analysis SST. These attributable SST changes are calculated on a monthly basis from the all-forcings and natural-forcings-only runs of three coupled Atmosphere-Ocean Global Climate Models from the fifth phase of the Coupled Model Intercomparison Project (CMIP5): CanESM2 for PIRa, GFDL-ESM2M (Geophysical Fluid Dynamics Laboratory) for PIRb and GISS-E2-H (Goddard Institute for Space Studies) for PIRc. Pre-industrial SIC is estimated using regression models relating SIC to SST (Pall et al. 2011), derived from CMC analysis.

Each ensemble consists of 240 members, initialized $3 \mathrm{~h}$ apart between 0000 UTC 01 September and 2100 UTC 30 September 2016, all continuing until 0000 UTC 19 May 2017. Initial conditions are taken from respective spin-up simulations, which start in early 2012, one for the presentday scenario and one for each pre-industrial scenario. The analysis focuses on comparing the present-day and preindustrial distributions of April precipitation, SWE, rain-onsnow and surface runoff values over the flood-affected basin.

\section{Meteorological and hydrological evolution, from observations and CRCM5}

As in most years, the land surface of the ORB was at least 95\% snow-covered in late March 2017, according to SNODAS. In addition, a large fraction of the top $60 \mathrm{~cm}$ of soil beneath the snow is modelled to have been mostly frozen, implying very low hydraulic conductivities. The snow depth over the basin on the first day of April was slightly above average when compared to the 1981-2010 period in both observations and CRCM5 (Fig. 3, left column).

Observed and modelled precipitation was much above average over the ORB in April (Fig. 3, middle column). Most of this precipitation fell as rain and an important fraction of this rainfall occurred over snow-covered areas, resulting in an intense rain-on-snow event that exceeded $100 \mathrm{~mm}$ over large areas of the basin (Fig. 4). Due to the low infiltration capacity of frozen soils, a large fraction of the snowmelt and heavy rainfall over the ORB during April is modelled to have entered the surface channels, resulting in a rapid increase of streamflow at the outlet during most of the month. This is consistent with observed water levels at the outlet of the Ottawa River, which increased from near normal at the beginning of April to near record-high towards the end of the month.

The heavy precipitation during April appears to have been controlled by large-scale features. Above-average temperatures over the ORB during April (Fig. 3, right column) are consistent with the frequent advection of warm and moist air from southerly regions. Low-level $(850 \mathrm{hPa})$ circulation anomalies from the ERA-Interim reanalysis (Fig. 5a) reveal
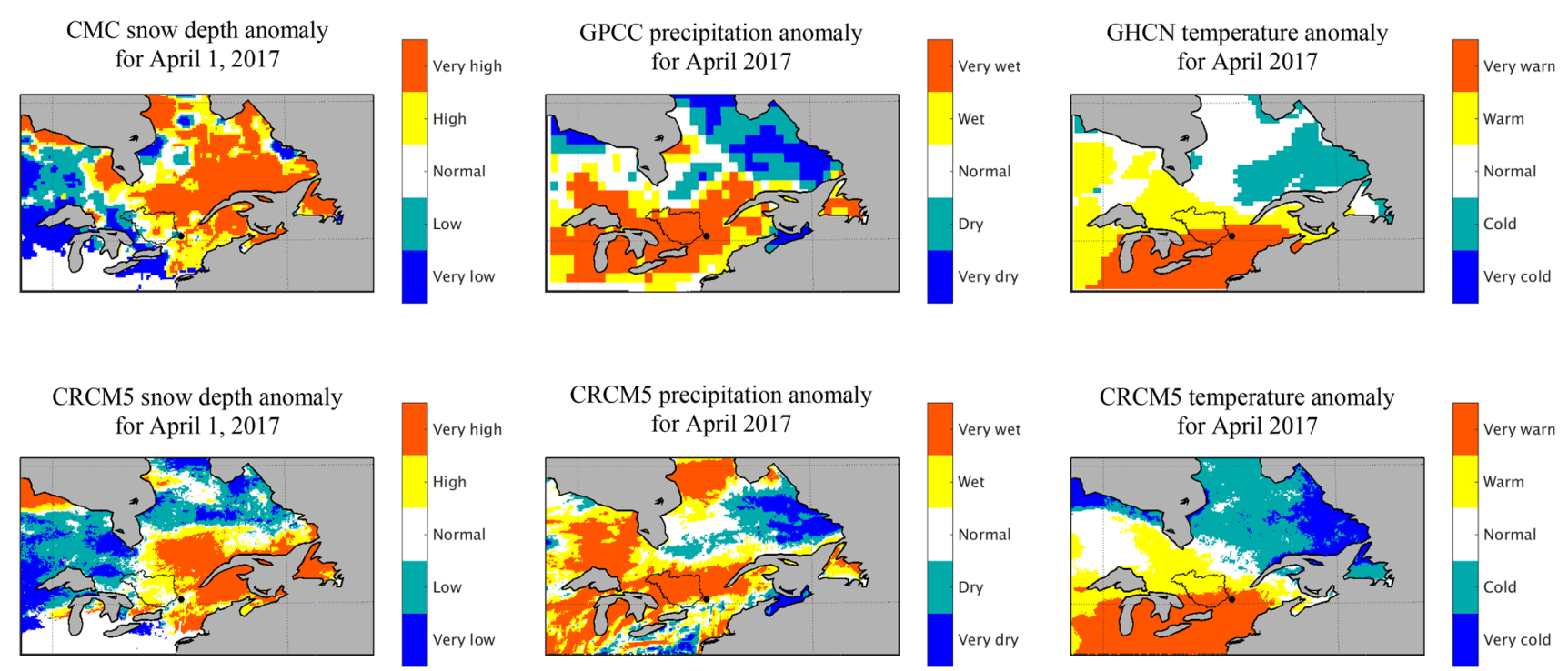

Fig. 3 April 2017 snow depth, precipitation and near-surface temperature anomalies with respect to 1981-2010 averages, shown as quintiles. Top row shows estimates from observational datasets, bottom row is based on CRCM5. The black dot denotes the location of Montreal 
Rainfall

SNODAS

CRCM5
Rain-on-snow
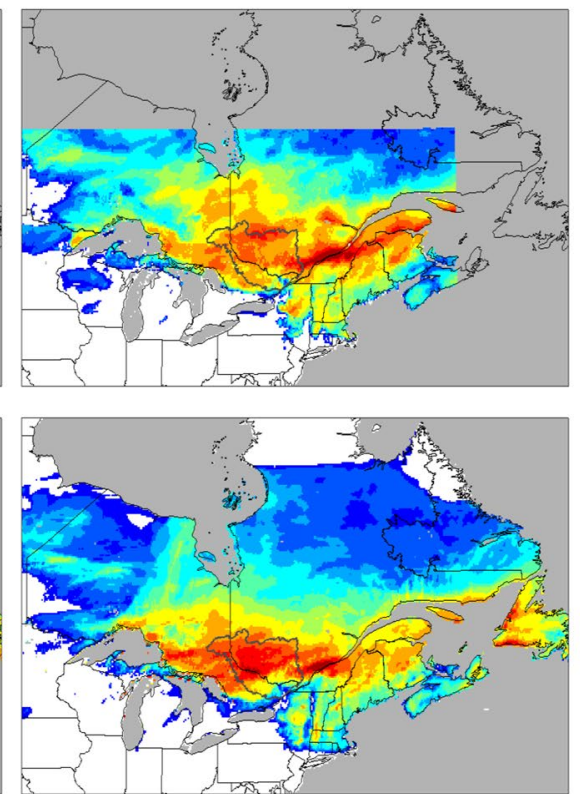

$\mathrm{mm}$

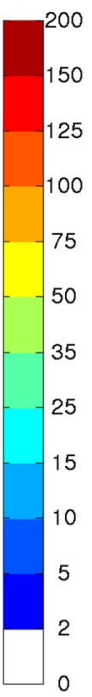

Fig. 4 April 2017 rainfall and rain-on-snow, from SNODAS (top row) and CRCM5 reference ensemble (bottom row)

Fig. 5 Wind anomalies at $850 \mathrm{hPa}($ left) and $200 \mathrm{hPa}$ (right) during April 2017, with respect to the 1981-2010 average, from the ERA-Interim reanalysis. Shading corresponds to anomalies in sea level pressure (left) and $500 \mathrm{hPa}$ geopotential height (right). The black dot denotes the location of Montreal
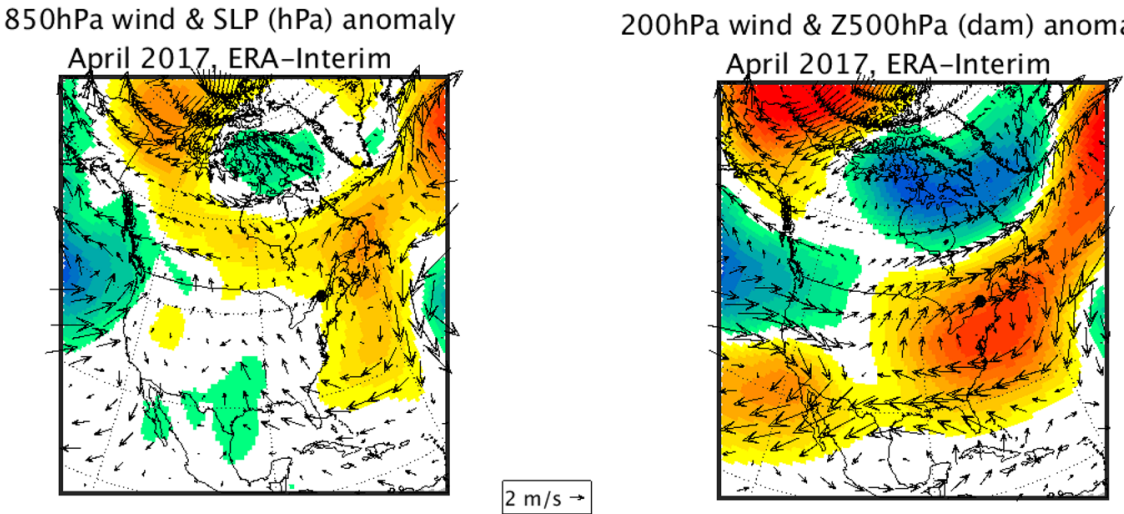

$4 \mathrm{~m} / \mathrm{s} \rightarrow$

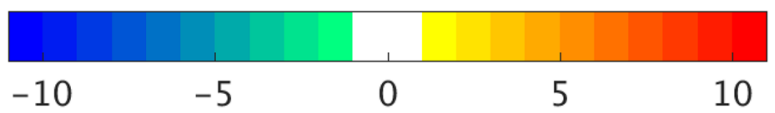

anticyclonic flow offshore the eastern coast of the United States, resulting in southerly anomalies over the ORB during April, conducive to supplying moisture. In the upper levels (200 hPa; Fig. 5b), an anomalous anticyclonic circulation centered near the east coast of the US results in a strongerthan-usual jet stream and enhanced upper-level divergence over the $\mathrm{ORB}$, conducive to generating precipitation due to the increase in upward vertical motion.

Two heavy rainfall events affected the ORB, during 30 April to 2 May, and during 5-6 May (Fig. 6). Both the model and estimates from CaPA agree that the total precipitation accumulation during these events exceeds $100 \mathrm{~mm}$ over large parts of the basin, being comparable to an average month's worth of precipitation. Both precipitation events are associated with low-level cyclones propagating into southern Quebec (Fig. 7). During the first event, the low tracks northeastward from the central US to northern Quebec, and is associated with southwesterly low-level winds over the ORB. During the second event, the low tracks closer to the eastern seaboard and is associated with low-level southerly winds over the eastern part of the ORB. In both cases, a strong upper-level jet provides divergence resulting in upward vertical motion and thus enhancing the generation of precipitation. These features are very well captured by the 
(a)
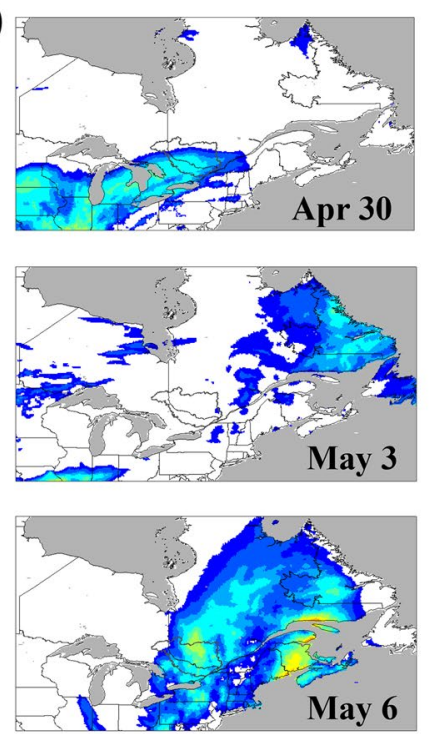

(b)
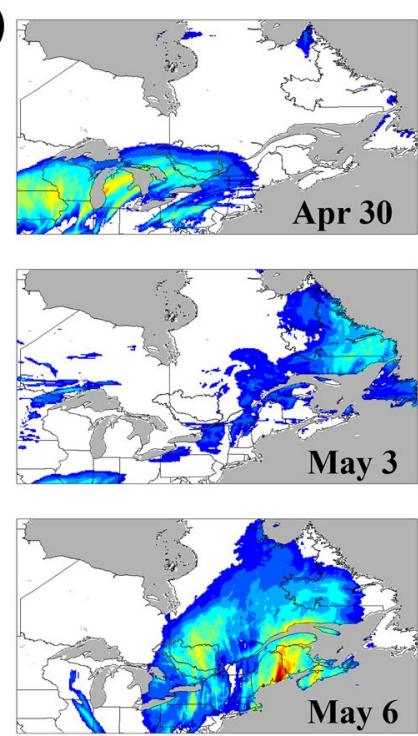
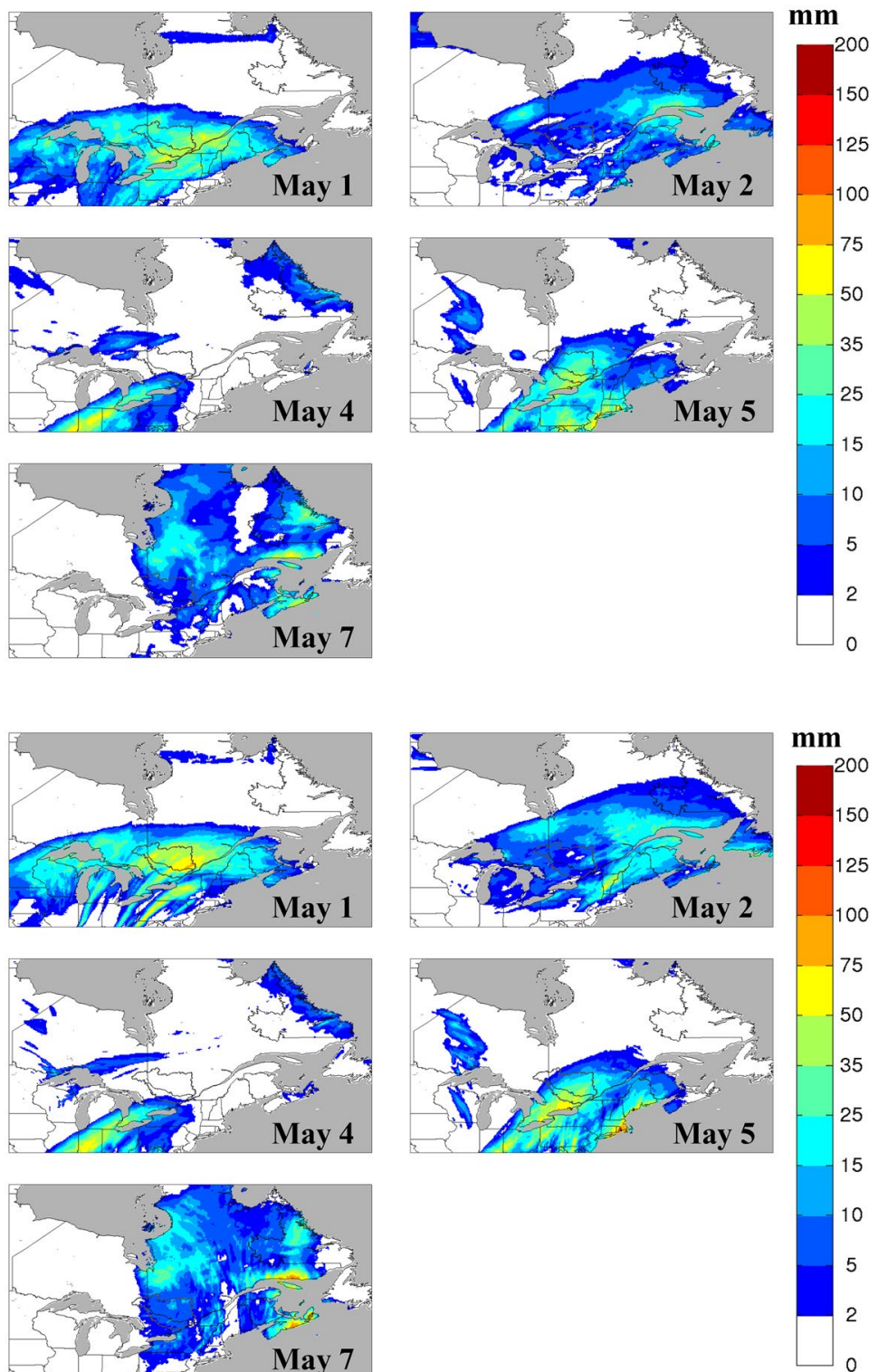

Fig. 6 Daily precipitation for 30 April-7 May, from $\mathbf{a}$ CaPA and $\mathbf{b}$ the CRCM5 reference ensemble

model, aided by the constraints imposed by spectral nudging (not shown).

On the hydrological side, while the snow had mostly melted by 30 April, the soil remained partly frozen for large parts of the ORB, resulting in low infiltration capacity. This allowed an important fraction of the rain that fell during the first week of May to reach surface channels that were already close to their maximum capacity, ultimately resulting in flooding. Figure 8 summarizes the modelled and observed evolution of snow cover in the ORB during April and early May, as well as the occurrence of precipitation and the generation of runoff in the basin. It can be seen that the model performs well with respect to the phase, timing and intensity of precipitation when compared to SNODAS and CaPA. The evolution of snow cover is also well represented when compared to SNODAS, although the agreement decreases by late-April, once most of the snowpack has melted.

\section{Results from sensitivity experiments}

This section discusses the contribution of snow distribution and frozen soils to the hydrological flood. This is accomplished by comparing each sensitivity experiment ensemble (described in Sect. 3) to the CRCM5 reference ensemble. For each ensemble, the small spread between members confirms that model results are a direct effect of 
Fig. 7 Circulation at $850 \mathrm{hPa}$ (left column) and $200 \mathrm{hPa}$ (right column) during 01 May (top row) and 06 May (bottom row), from the ERA-Interim reanalysis. Shading corresponds to anomalies in sea level pressure (left column) and $500 \mathrm{hPa}$ geopotential height (right column). The black dot denotes the location of Montreal

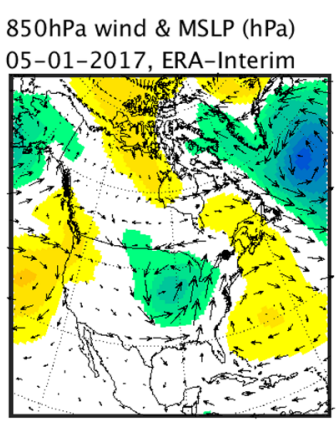

$0 \mathrm{~m} / \mathrm{s} \rightarrow$

200hPa wind \& Z500hPa (dam)

05-01-2017, ERA-Interim

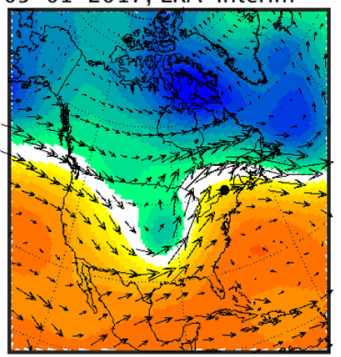

$20 \mathrm{~m} / \mathrm{s} \rightarrow$

$850 \mathrm{hPa}$ wind \& MSLP (hPa)

05-06-2017, ERA-Interim

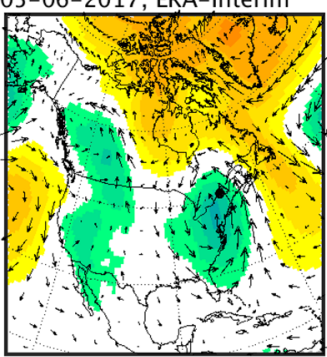

$10 \mathrm{~m} / \mathrm{s} \rightarrow$
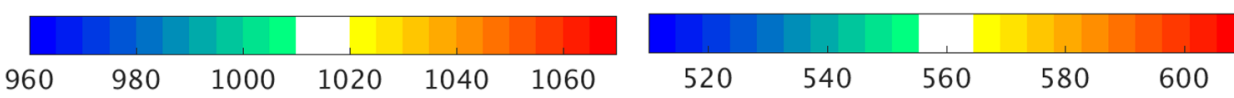

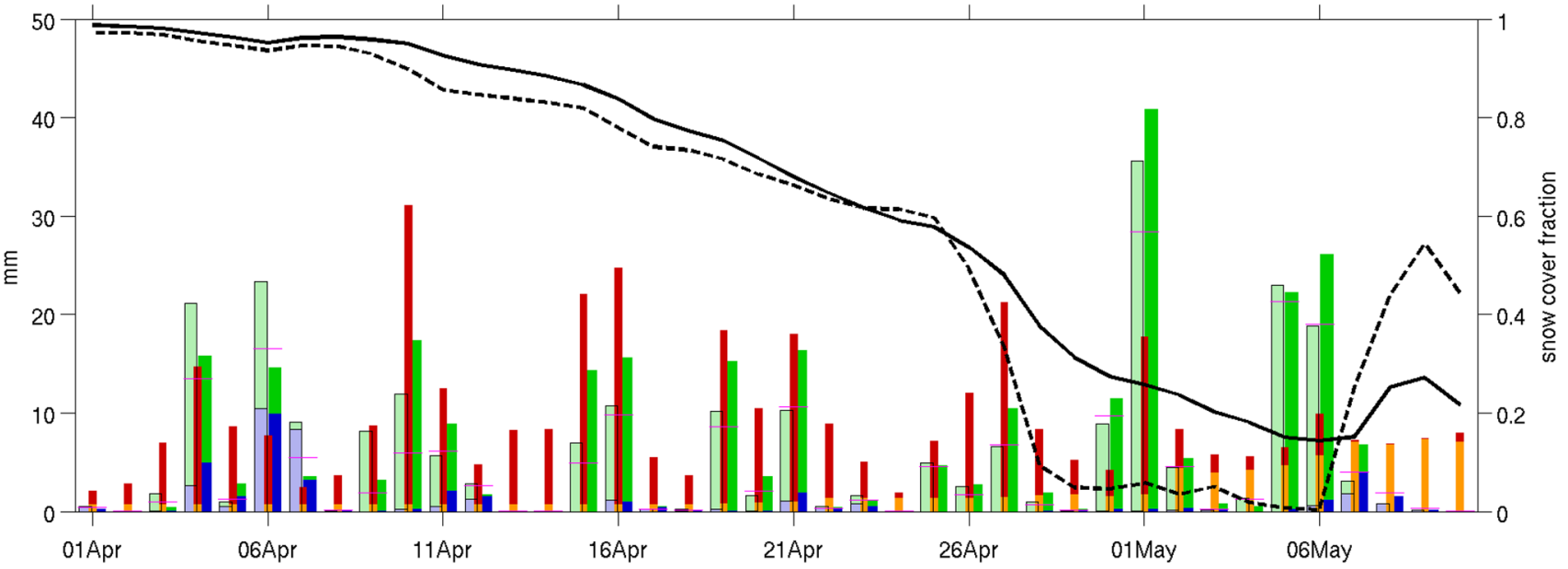

Fig. 8 Daily rainfall (dark green), water equivalent snowfall (dark blue), surface runoff (red) and drainage (orange) over the Ottawa River basin from CRCM5 reference ensemble. Also shown are daily rainfall (light green) and snowfall (light blue) from SNODAS and

boundary conditions and that spurious solutions of stochastic origin are being avoided, i.e., the magnitude of CRCM5 generated internal variability is small. The Wilcoxon-Mann-Whitney test is used to assess the statistical significance of the differences, with a 5\% significance level. daily precipitation from CaPA (magenta lines). Full and dashed lines show the snow cover evolution from CRCM5 and SNODAS, respectively

\subsection{Impact of snow mass and distribution on streamflow}

The comparison of streamflow at the outlet of the ORB between simulations prescribing initial SWE from a highsnow and a low-snow year, reveals that snow mass exerts a first order control on the magnitude of the peak flow, with 
the high-snow year reaching a peak flow of more than twice the magnitude of the peak flow in the low-snow year (Fig. 9). This result is not unexpected, as the high-snow year starts with around four times as much snow as the low-snow year, highlighting the large interannual variability of snow accumulation in this basin.

Even when conserving the same snow mass as the reference ensemble, prescribing a more heterogeneous snow distribution at the beginning of April results in a clear reduction of the streamflow at the outlet of the ORB during April. This is explained by the reduced snow cover leading to a smaller area of the basin contributing runoff from snowmelt during the first few weeks. However, as the snowpack is deeper, snow cover is maintained for longer and results in a continued increase of streamflow during early May. The opposite signal is seen when prescribing a more homogeneous snow cover, which leads to an increase in the rate of early melting and a higher peak flow, followed by a faster decline in flow, as the snowmelt contribution becomes small.

These results reflect the land use of the basin. Over an open landscape, the simulation with homogeneous snow would have significantly larger albedo, potentially leading to lower near-surface temperatures and slower snowmelt with respect to the simulation with heterogeneous snow. Over the mostly forested ORB, the albedo difference between homogeneous and heterogenous snow cover is small, leading to the modelled dominance of snow area over snow-albedo feedback.

\subsection{Impact of frozen soil parameterization on simulated streamflow}

There is a large impact of the improved parameterization of frozen soils on the evolution of modelled streamflow at the outlet of the ORB (Fig. 10). Only the reference ensemble with the improved parameterization is able to capture the reported rise of streamflow to near-record levels during April. In the ensemble without this improvement, surface runoff over the ORB is modelled to be significantly smaller, while drainage at the interface of the soil column with the bedrock is modelled to be much larger during the second half of April and early May. The lower surface runoff explains the slower rise in streamflow during April, while the higher drainage explains the continued rise in streamflow during May, as the water stored in the underground reservoir is released over the course of a few weeks. These results are consistent with those of Ganji et al. (2017) and confirm the importance of using an appropriate frozen soil parameterization when modelling spring streamflows in cold regions.

\section{Event attribution}

The 'attributable risk' approach to event attribution is used when comparing the present-day and pre-industrial distributions of April precipitation, SWE, rain-on-snow and runoff values over the flood-affected basin. Risk ratios corresponding to an event of certain magnitude are calculated by dividing the probability of exceedance of the event in present-day climate by the probability of exceedance of the same event in each of the pre-industrial ensembles. It follows that a risk ratio above unity corresponds to events

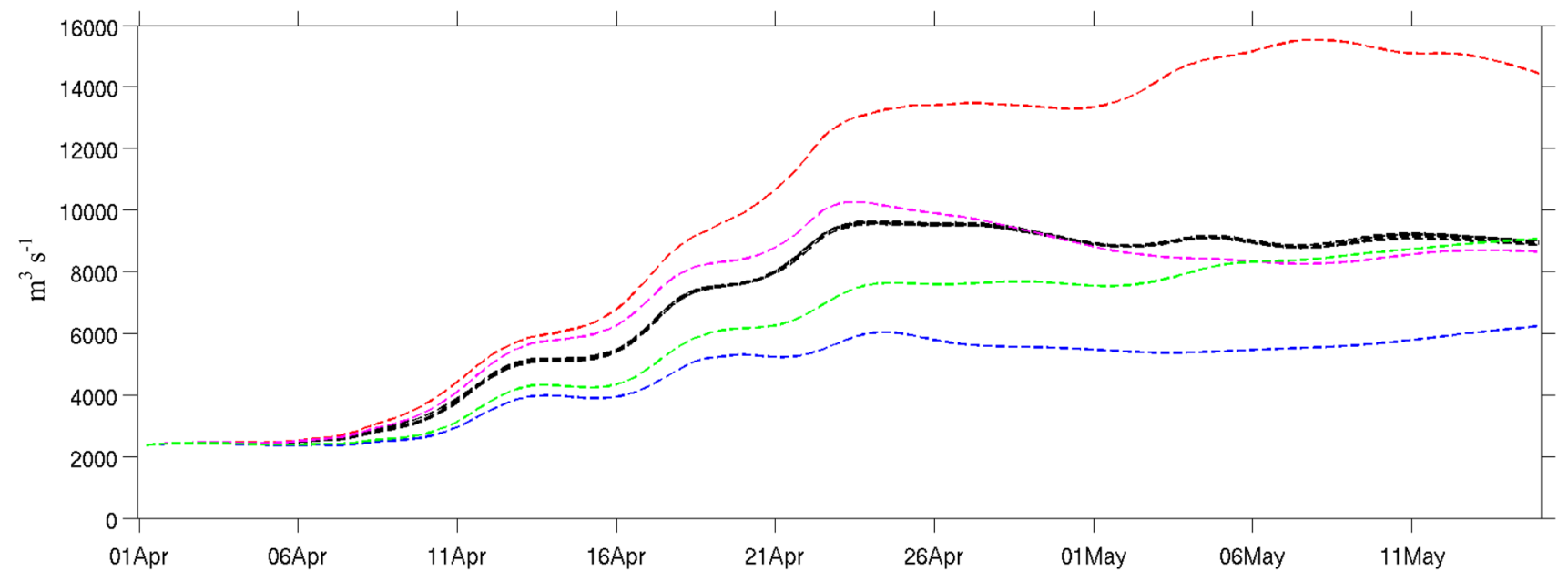

Fig. 9 Streamflow at the outlet of the ORB from the CRCM5 reference ensemble (black), from simulations initialized with high snow (red) and low snow (blue), and from simulations initialized with homogeneous (magenta) and heterogeneous (green) snowpacks, while conserving the same snow mass as the reference ensemble 


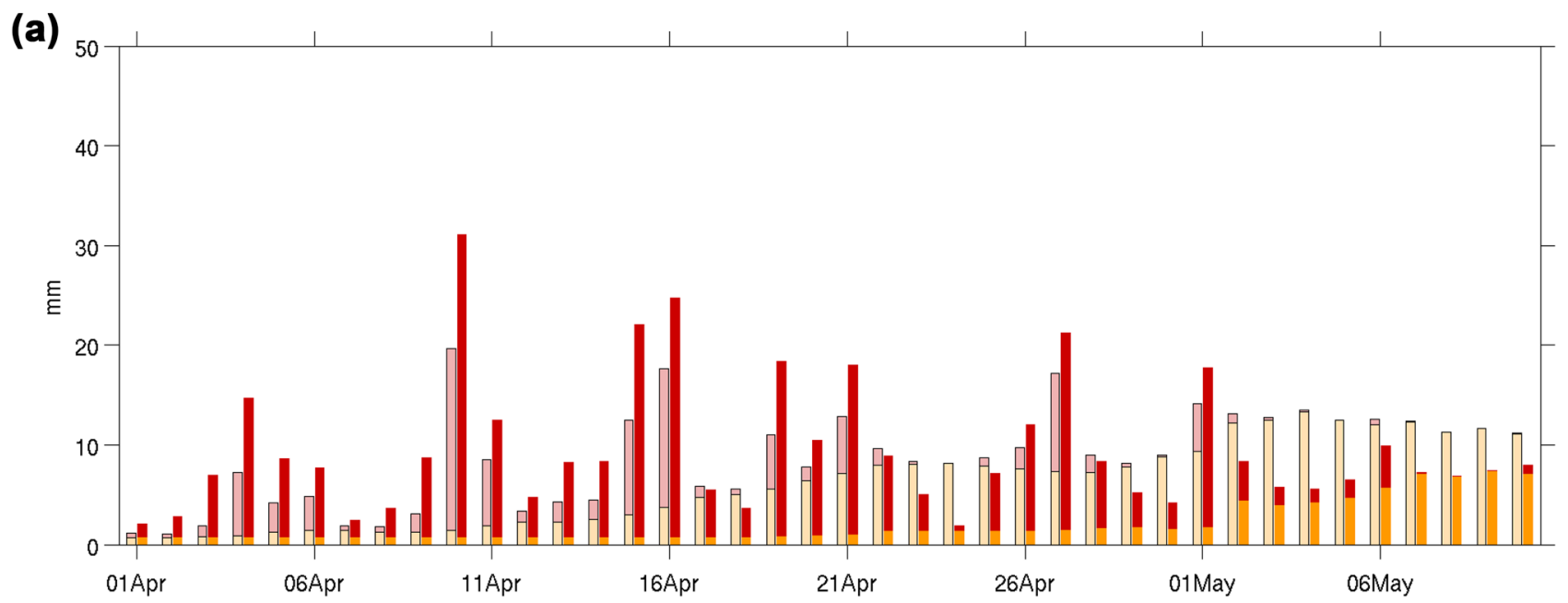

(b)

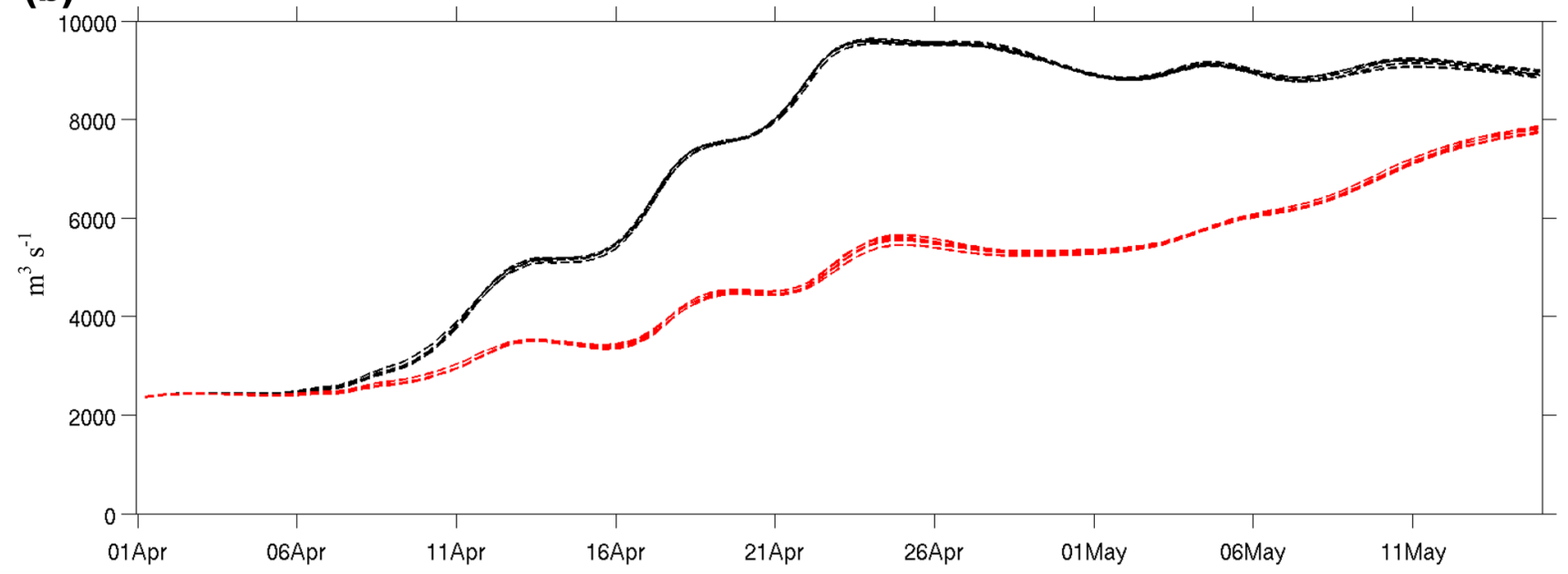

Fig. 10 a Daily surface runoff (red) and drainage at the soil/bedrock interface (yellow) over the Ottawa River basin from the CRCM5 reference ensemble (dark colors) and from an ensemble without improved frozen soil parameterization (light colors). b Streamflow at

that are more likely to occur in present-day climate, while a risk ratio below unity is obtained for events less likely to occur in present-day climate than in the pre-industrial climate.

Significant influence of anthropogenic emissions on total precipitation over the ORB during the month of April is detected, with the best estimate being that events such as the April 2017 precipitation accumulation are between two and three times as likely to occur in present-day climate, when compared to the pre-industrial climate (Fig. 11a). The anthropogenic signal is even stronger for April rainfall (Fig. 11b), as higher temperatures in the present-day ensemble favor the liquid phase of precipitation. These higher temperatures are also associated with a significant reduction in the mass of the snowpack at the beginning of April, with snowpacks similar to that of 2017 being around half as likely the outlet of the ORB from the CRCM5 reference ensemble (black) and from an ensemble without improved frozen soil parameterization (red)

to occur in the present-day climate than in the pre-industrial climate (Fig. 11c).

Due to the counterbalancing effects of increased rainfall and reduced snowpack, no significant differences can be detected in April rain-on-snow accumulation, nor total runoff (Fig. 11d, f). As the reduction in snowpack mass also favors earlier thawing of the soil column, increasing infiltration rates, small reductions in surface runoff can be detected for many events, but there is no change detected for events above the 90th percentile (10-year return time), which can be interpreted as no change in spring flood risk (Fig. 11e).

The present-day and pre-industrial ensembles also present an opportunity to study the mechanisms favoring heavy precipitation over the ORB in April and early May, which are likely to have played a role in the 2017 flood. This analysis focuses on the inter-member variability in the present-day 

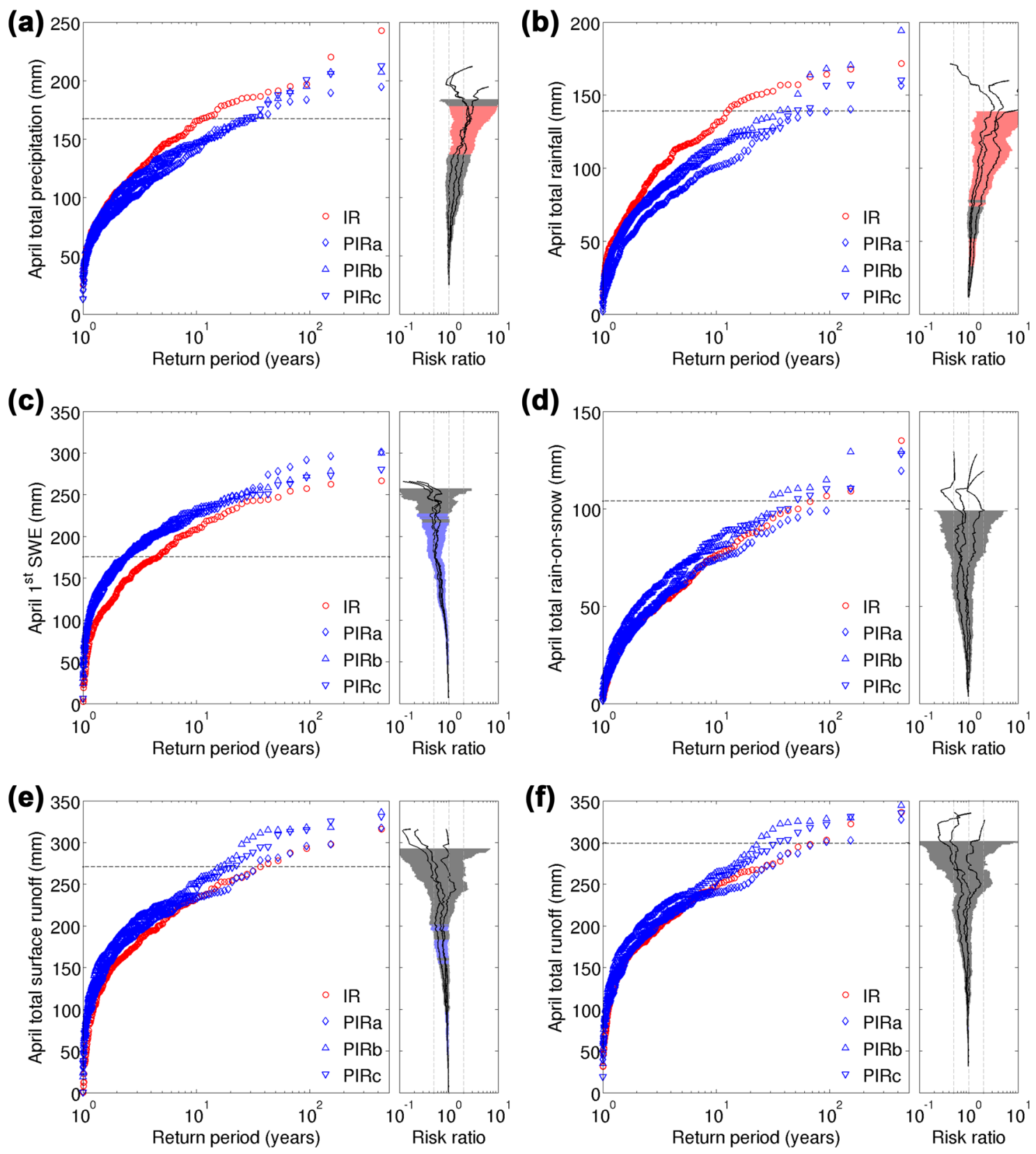

Fig. 11 Return times of April a total precipitation, $\mathbf{b}$ rainfall, $\mathbf{c}$ snow water equivalent at the beginning of the month, $\mathbf{d}$ rain-on-snow, $\mathbf{e}$ surface runoff and $\mathbf{f}$ total runoff in present-day (red) and pre-industrial ensembles (blue), over the Ottawa River basin. Black dashed lines correspond to the mean of the CRCM5 reference ensemble for April

and each of the pre-industrial ensembles and attempts to tease out the features associated with heavy precipitation over the ORB during the snowmelt season.

Precipitation over the ORB in April exhibits a strong positive correlation with vertically integrated water vapour above the ORB and regions to the southeast (Fig. 12), implying that atmospheric moisture over these regions may have contributed to precipitation over the basin. Precipitation

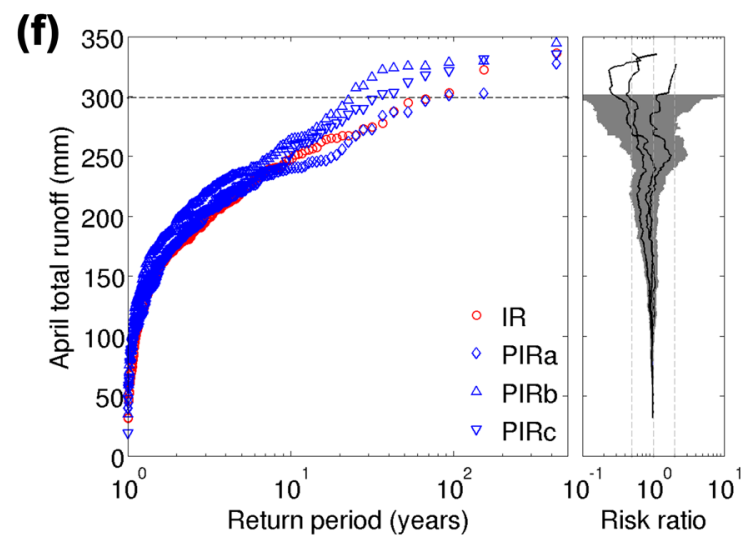

2017. Risk ratios calculated from each of the pre-industrial ensembles are shown as black solid lines, along with their $95 \%$ confidence intervals (CI). Red shading is used when the lower bound of the CI exceeds one, blue shading is used when the upper bound of the $\mathrm{CI}$ is less than one, and grey shading is used otherwise

over the ORB also is positively correlated with sea level pressure (SLP) off the east coast of the United States, and negatively correlated to SLP over the Great Lakes, which both favor low-level southerly flow into the ORB, conducive to high precipitation. Finally, precipitation over the ORB is also positively correlated with $200-\mathrm{hPa}$ divergence over the basin, which favors upward motion in the troposphere. When combined, these patterns explain most of the inter-member 


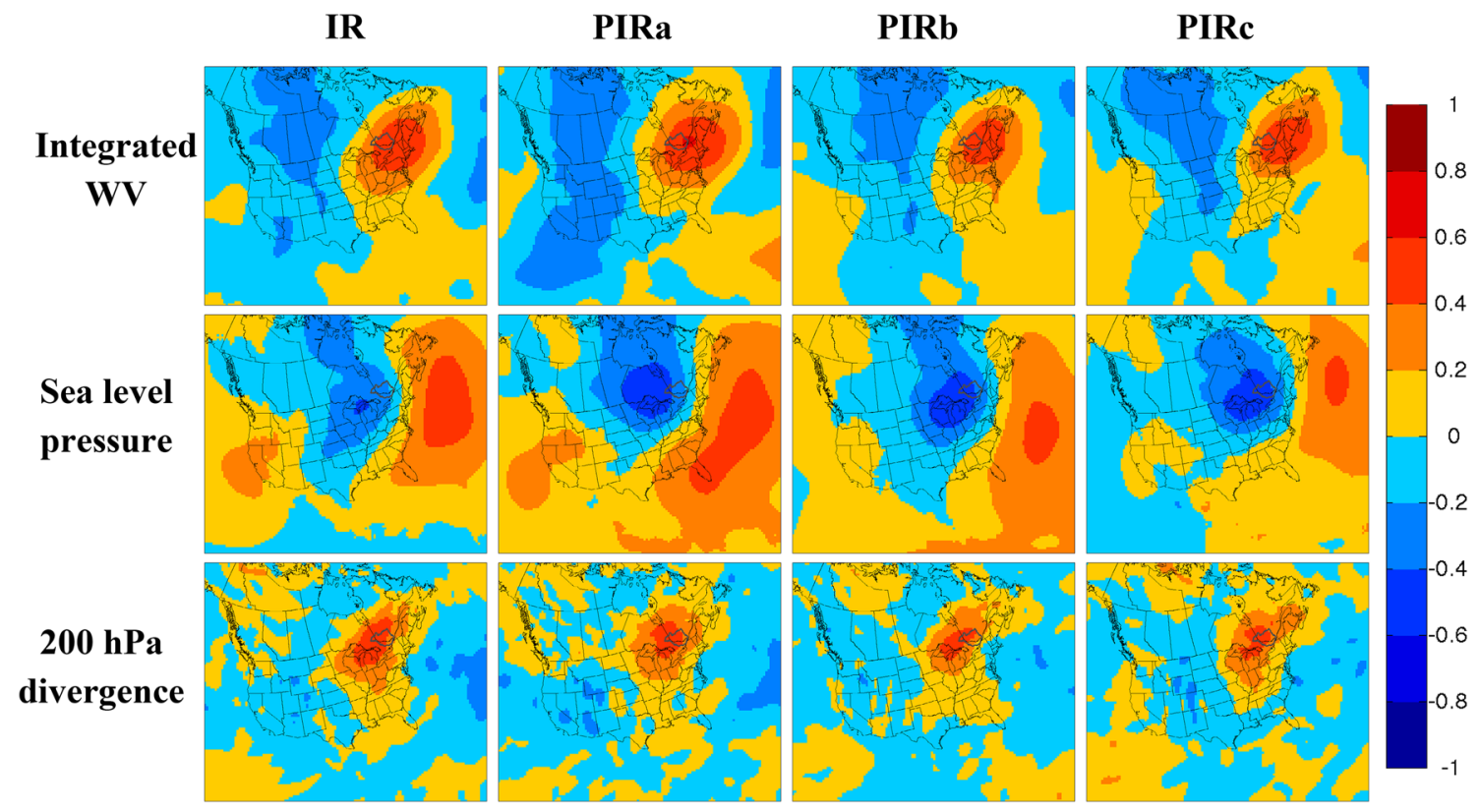

Fig. 12 Linear correlation between April precipitation over the ORB and vertically integrated water vapour (top row), sea level pressure (middle row) and $200 \mathrm{hPa}$ divergence (bottom row), calculated for each grid cell in the present-day (IR) and pre-industrial (PIRa, PIRb, PIRc) ensembles

variability of April precipitation, supporting the conclusion that large scale features have a strong control on precipitation over the ORB, as they did in 2017.

The strength of these correlations involving precipitation over the ORB does not change significantly between the present-day and pre-industrial ensembles, suggesting that the rain-generating mechanisms in April remain very similar. A comparison of the present-day and preindustrial vertically integrated water vapour over the

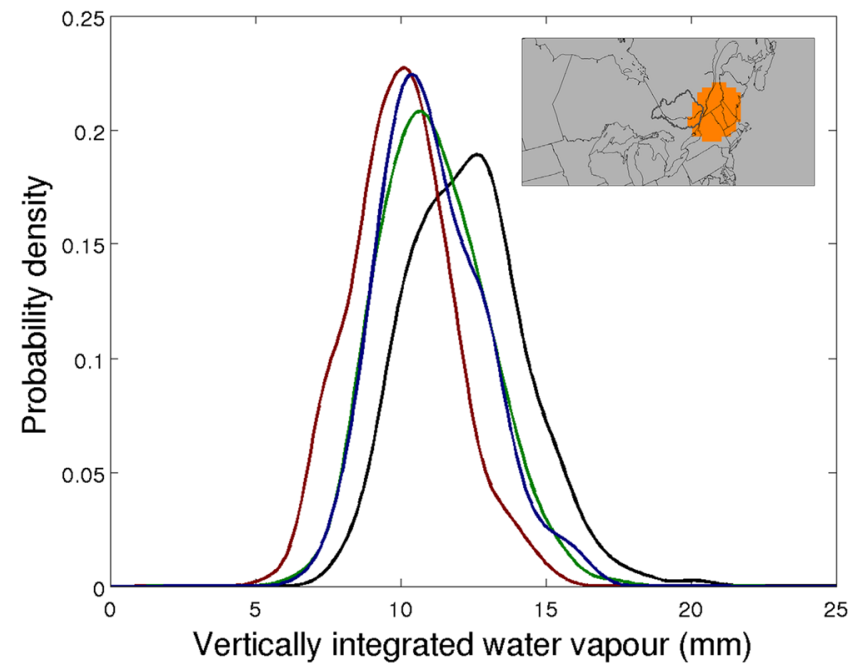

Fig. 13 Probability distributions of vertically integrated water vapour (left) and $200 \mathrm{hPa}$ divergence (right) in the present-day ensemble (black line) and each of the pre-industrial ensembles (coloured lines). region where the correlation with ORB precipitation is strongest, reveals an increase in available moisture for the present-day ensemble (Fig. 13). In contrast, a similar analysis involving 200-hPa divergence suggests little difference between present-day and pre-industrial ensembles. From this analysis, it appears that the increase in the risk of heavy precipitation events over the ORB is linked to increased atmospheric moisture due to warmer

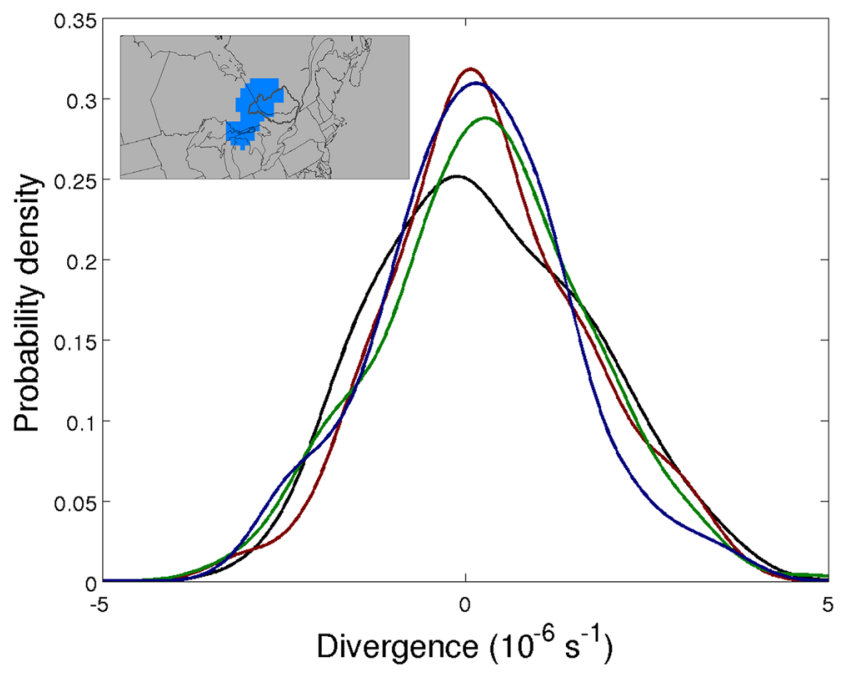

The insets show the regions for which the probability distributions are obtained, and correspond to the regions of maximum correlation for each variable from Fig. 12 
temperatures in the present-day ensemble, rather than changes in rain-generating mechanisms or circulation patterns.

\section{Summary and conclusions}

This study has explored the mechanisms behind the extreme discharge from the Ottawa River basin that caused destructive flooding near Montreal during the first half of May 2017. This was accomplished through the analysis of observations and CRCM5 experiments. The model realistically represents most of the factors leading to the flood, including the much above average April precipitation and the associated heavy rain-on-snow event, which increased streamflow to near record-high levels. The two heavy rainfall events affecting the ORB in the first week of May, which ultimately resulted in flooding, are also well represented.

Sensitivity experiments with CRCM5 confirmed the importance of using an appropriate frozen soil parameterization when modelling spring streamflows in cold regions. In addition, results from experiments altering the snow mass and distribution at the beginning of the snowmelt season suggest that the state of the snowpack has a strong control on spring streamflow in the ORB and similar basins.

Event attribution using CRCM5 showed that events such as the observed April 2017 precipitation accumulation over the ORB are between two and three times as likely to occur in present-day climate than in the pre-industrial climate. This increase in the risk of heavy precipitation is linked to increased atmospheric moisture due to warmer temperatures that are a direct consequence of anthropogenic emissions. Warmer temperatures are also associated with a significant reduction in the mass of the snowpack at the beginning of April in the present-day climate, which offsets the increase in rainfall and results in no change to the likelihood of extreme surface runoff, a proxy for flood risk. It can be speculated that in a future (warmer) climate, further decrease in the mass of the snowpack, along with increases in infiltration rate due to soils thawing earlier, may outpace possible increases in rainfall, thus reducing the risk of spring flooding (e.g., Musselman et al. 2017), although previous studies over the ORB (e.g., Clavet-Gaumont et al. 2013; Huziy et al. 2013) did not project significant changes to peak streamflow.

To realistically simulate flooding extent, hydraulic modelling is required, which would also allow the quantification of other factors that may have played a role in the flood and which are not considered in the present study, such as the high discharge from the Great Lakes. In addition, the uncertainties in snow mass/distribution and soil water/ice content could be taken into account. Another interesting avenue of future research involves the influence of SST patterns on the flood, which is speculated to be at least discernible, given the spread among the pre-industrial ensembles observed in this study.

Acknowledgements This work was carried out within the framework of the Natural Sciences and Engineering Research Council of CanadaClimate Change and Atmospheric Research (NSERC-CCAR) Program funded Canadian Network for Regional Climate and Weather Processes (CNRCWP). The simulations considered in this study were performed on the supercomputer managed by Calcul Québec and Compute Canada. Global analysis files were provided by the Canadian Meteorological Centre.

Open Access This article is distributed under the terms of the Creative Commons Attribution 4.0 International License (http://creativeco mmons.org/licenses/by/4.0/), which permits unrestricted use, distribution, and reproduction in any medium, provided you give appropriate credit to the original author(s) and the source, provide a link to the Creative Commons license, and indicate if changes were made.

\section{References}

Alexandru A, de Elia R, Laprise R, Separovic L, Biner S (2009) Sensitivity study of regional climate model simulations to large-scale nudging parameters. Mon Weather Rev 137(5):1666-1686. https ://doi.org/10.1175/2008MWR2620.1

Barrett AP (2003) National operational hydrologic remote sensing center snow data assimilation system (SNODAS) products at NSIDC: National Snow and Ice Data Center, Cooperative Institute for Research in Environmental Sciences

Belair S, Mailhot J, Girard C, Vaillancourt P (2005) Boundary layer and shallow cumulus clouds in a medium-range forecast of a large-scale weather system. Mon Weather Rev 133(7):1938-1960. https://doi.org/10.1175/Mwr2958.1

Benoit R, Cote J, Mailhot J (1989) Inclusion of a Tke boundarylayer parameterization in the Canadian regional finite-element model. Mon Weather Rev 117(8):1726-1750. https://doi. org/10.1175/1520-0493(1989)117\%3C1726:Ioatb1\%3E2.0.Co;2

Caron LP, Jones CG, Winger K (2011) Impact of resolution and downscaling technique in simulating recent Atlantic tropical cylone activity. Clim Dyn 37(5-6):869-892. https://doi.org/10.1007/ s00382-010-0846-7

Christidis N, Stott PA, Scaife AA, Arribas A, Jones GS, Copsey D, Knight JR, Tennant WJ (2013) A new HadGEM3-A-based system for attribution of weather- and climate-related extreme events. J Clim 26(9):2756-2783. https://doi.org/10.1175/Jcli-D-12-00169.1

Clavet-Gaumont J, Sushama L, Khaliq MN, Huziy O, Roy R (2013) Canadian RCM projected changes to high flows for Québec watersheds using regional frequency analysis. Int J Climatol 33(14):2940-2955. https://doi.org/10.1002/joc.3641

Cote J, Gravel S, Methot A, Patoine A, Roch M, Staniforth A (1998) The operational CMC-MRB global environmental multiscale (GEM) model. Part I: Design considerations and formulation. Mon Weather Rev 126(6):1373-1395. https://doi.org/10.1175/15200493(1998)126\%3C1373:Tocmge\%3E2.0.Co;2

Dee DP, Uppala SM, Simmons AJ, Berrisford P, Poli P, Kobayashi S, Andrae U, Balmaseda MA, Balsamo G, Bauer P, Bechtold P, Beljaars ACM, van de Berg L, Bidlot J, Bormann N, Delsol C, Dragani R, Fuentes M, Geer AJ, Haimberger L, Healy SB, Hersbach H, Holm EV, Isaksen L, Kallberg P, Kohler M, Matricardi M, McNally AP, Monge-Sanz BM, Morcrette JJ, Park BK, Peubey 
C, de Rosnay P, Tavolato C, Thepaut JN, Vitart F (2011) The ERA-Interim reanalysis: configuration and performance of the data assimilation system. Q J R Meteorol Soc 137(656):553-597. https://doi.org/10.1002/qj.828

Delage Y (1997) Parameterising sub-grid scale vertical transport in atmospheric models under statically stable conditions. Bound Layer Meteorol 82(1):23-48. https://doi.org/10.1023/A:10001 32524077

Delage Y, Girard C (1992) Stability functions correct at the free-convection limit and consistent for both the surface and Ekman layers. Bound-Layer Meteorol 58(1-2):19-31. https://doi.org/10.1007/ Bf00120749

Ganji A, Sushama L, Verseghy D, Harvey R (2017) On improving cold region hydrological processes in the Canadian Land Surface Scheme. Theoret Appl Climatol 127(1):45-59. https://doi. org/10.1007/s00704-015-1618-4

Huziy O, Sushama L, Khaliq MN, Laprise R, Lehner B, Roy R (2013) Analysis of streamflow characteristics over Northeastern Canada in a changing climate. Clim Dyn 40(7):1879-1901. https://doi. org/10.1007/s00382-012-1406-0

Insurance Bureau of Canada (2017) Spring flooding in Ontario and Quebec caused more than $\$ 223$ million in insured damage [Press release]. http://www.ibc.ca/on/resources/media-centre/media -releases/spring-flooding-in-ontario-and-quebec-caused-morethan-223-million-in-insured-damage

Kain JS, Fritsch JM (1990) A one-dimensional entraining detraining plume model and its application in convective parameterization. J Atmos Sci 47(23):2784-2802. https://doi.org/10.1175/15200469(1990)047\%3C2784:Aodepm\%3E2.0.Co;2

Kay AL, Crooks SM, Pall P, Stone DA (2011) Attribution of Autumn/ Winter 2000 flood risk in England to anthropogenic climate change: a catchment-based study. J Hydrol 406(1-2):97-112. https ://doi.org/10.1016/j.jhydrol.2011.06.006

Kuo, H. L. (1965). On Formation and Intensification of Tropical Cyclones through Latent Heat Release by Cumulus Convection. J Atmos Sci 22(1):40. https://doi.org/10.1175/15200469(1965)022\%3C0040:Ofaiot\%3E2.0.Co;2

Laprise, R. (1992). The Euler equations of motion with hydrostatic-pressure as an independent variable. Mon Weather Rev 120(1):197-208. https://doi.org/10.1175/15200493(1992)120\%3C0197:Teeomw\%3E2.0.Co;2

Lehner B, Verdin K, Jarvis A (2008) New global hydrography derived from spaceborne elevation data. Eos Trans Am Geophys Union 89(10):93-94. https://doi.org/10.1029/2008EO100001

Li J, Barker HW (2005) A radiation algorithm with correlated-k distribution. Part I: Local thermal equilibrium. J Atmos Sci 62(2):286309. https://doi.org/10.1175/Jas-3396.1

Madec G (2008) NEMO reference manual, ocean dynamic component: NEMO-OPA. Note du Pôle de modélisation, Institut Pierre Simon Laplace, France, Technical Report, 27

Mahfouf JF, Brasnett B, Gagnon S (2007) A Canadian precipitation analysis (CaPA) project: description and preliminary results. Atmos Ocean 45(1):1-17

Markovic M, Lin H, Winger K (2012) Dynamical seasonal prediction using the global environmental multiscale model with a variable resolution modeling approach. Clim Dyn 39(7-8):1885-1904. https://doi.org/10.1007/s00382-011-1202-2

Martynov A, Laprise R, Sushama L, Winger K, Separovic L, Dugas B (2013) Reanalysis-driven climate simulation over CORDEX North
America domain using the Canadian Regional Climate Model, version 5: model performance evaluation. Clim Dyn 41(1112):2973-3005. https://doi.org/10.1007/s00382-013-1778-9

Mcfarlane NA (1987) The effect of orographically excited gravitywave drag on the general-circulation of the lower stratosphere and troposphere. J Atmos Sci 44(14):1775-1800. https://doi. org/10.1175/1520-0469(1987)044\%3C1775:Teooeg\%3E2.0.Co;2

Mironov DV (2008) Parameterization of lakes in numerical weather prediction. Part 1: Description of a lake model

Musselman KN, Clark MP, Liu C, Ikeda K, Rasmussen R (2017) Slower snowmelt in a warmer world. Nat Clim Change 7:214. https://doi.org/10.1038/nclimate3225

Pall P, Aina T, Stone DA, Stott PA, Nozawa T, Hilberts AGJ, Lohmann D, Allen MR (2011) Anthropogenic greenhouse gas contribution to flood risk in England and Wales in autumn 2000. Nature 470(7334):382-385. https://doi.org/10.1038/nature09762

Poitras V, Sushama L, Seglenieks F, Khaliq MN, Soulis E (2011) Projected changes to streamflow characteristics over Western Canada as simulated by the Canadian RCM. J Hydrometeorol 12(6):13951413. https://doi.org/10.1175/Jhm-D-10-05002.1

Québec Government (2017) Forum Inondations 2017-Ensemble, planifions l'avenir autrement [Press release]. http://www.mddel cc.gouv.qc.ca/infuseur/communique_en.asp?no $=3856$

Soulis ED, Snelgrove KR, Kouwen N, Seglenieks F, Verseghy DL (2000) Towards closing the vertical water balance in Canadian atmospheric models: coupling of the land surface scheme CLASS with the distributed hydrological model WATFLOOD. Atmos Ocean 38(1):251-269

Storch HV, Langenberg H, Feser F (2000) A spectral nudging technique for dynamical downscaling purposes. Mon Weather Rev 128(10):3664-3673. https://doi.org/10.1175/15200493(2000)128\%3C3664:asntfd\%3E2.0.co;2

Stott PA, Stone DA, Allen MR (2004) Human contribution to the European heatwave of 2003. Nature 432:610. https://doi.org/10.1038/ nature 03089

Sundqvist H, Berge E, Kristjansson JE (1989) Condensation and cloud parameterization studies with a mesoscale numerical weather prediction model. Mon Weather Rev 117(8):1641-1657. https://doi. org/10.1175/1520-0493(1989)117\%3C1641:Cacpsw\%3E2.0.Co;2

Teufel B, Diro GT, Whan K, Milrad SM, Jeong DI, Ganji A, Huziy O, Winger K, Gyakum JR, de Elia R, Zwiers FW, Sushama L (2017) Investigation of the 2013 Alberta flood from weather and climate perspectives. Clim Dyn 48(9):2881-2899. https://doi.org/10.1007/ s00382-016-3239-8

Verseghy DL (2011) CLASS-The Canadian Land Surface Scheme (Version 3.5), Technical Documentation (Version 1). Climate Research Division, Science and Technology Branch, Environment Canada

Yeh KS, Cote J, Gravel S, Methot A, Patoine A, Roch M, Staniforth A (2002) The CMC-MRB global environmental multiscale (GEM) model. Part III: Nonhydrostatic formulation. Mon Weather Rev 130(2):339-356. https://doi.org/10.1175/15200493(2002)130\%3C0339:Tcmgem\%3E2.0.Co;2

Zadra A, Roch M, Laroche S, Charron M (2003) The subgrid-scale orographic blocking parametrization of the GEM model. Atmos Ocean 41(2):155-170. https://doi.org/10.3137/ao.410204 